\title{
OCORRÊNCIA DE FUNGOS MICORRÍZICOS ARBUSCULARES, NEMATÓIDES E ÁCAROS EM SOLOS SOB DIFERENTES SISTEMAS DE CULTIVO CAFEEIRO NO SUL DE MINAS GERAIS
}

\section{OCCURRENCE OF ARBUSCULAR MYCORRHIZAL FUNGI, NEMATODES AND ACARIS IN SOIL OF DIFFERENT COFFEE CROP SYSTEMS IN SOUTH OF MINAS GERAIS}

\begin{abstract}
Erika Matos Teixeira - Tecnóloga em Meio Ambiente, IF Sul de Minas - Campus Inconfidentes. erika.mt@hotmail.com; Luiz Carlos Dias Rocha-Prof. D.Sc. IF Sul de Minas - Campus Inconfidentes.

Praça Tiradentes, 416, Centro, 37576-000.luiz.rocha@ifs.ifsuldeminas.edu.br;

Thaís de Faria Machado - Tecnóloga em Meio Ambiente, IF Sul de Minas - Campus Inconfidentes. tfmambiental@gmail.com; Jamil de Morais Pereira-Prof. M.Sc. IF Sul de Minas - Campus Inconfidentes. labrademinas@gmail.com; Felipe Moreton Chohfi-Prof. M.Sc. IF Sul de Minas - Campus Inconfidentes. fmchohfi@feq.unicamp.br; Verônica Soares de Paula Morais-Profa.M.Sc. IF Sul de Minas -
\end{abstract} Campus Inconfidentes.veronicaspm@gmail.com.

\section{RESUMO}

O presente trabalho teve como objetivo estudar ocorrência de FMAs, nematóides e ácaros em solos sob diferentes sistemas de cultivo cafeeiro no Sul de Minas Gerais, em quatro estações distintas: verão, outono, inverno e primavera. Foram amostradas áreas sob sistema de cultivo cafeeiro safra-zero, convencional e orgânico. Para cada uma das amostras de solo coletadas na camada de 0 a $20 \mathrm{~cm}$ realizou-se a extração de esporos, nematóides e ácaros, adotando-se a técnica do peneiramento úmido seguido de centrifugação em sacarose a 50\%. A contagem dos microrganismos foi realizada por meio de uma placa canaletada, com auxílio de microscópio estereoscópico. As práticas de manejo ou sistemas de cultivo adotado em cada uma das três áreas em estudo apresentaram influência na variação da densidade dos microrganismos analisados nas quatro estações do ano. A maior densidade de esporos foi obtida no solo sob sistema orgânico no período do outono e a menor média foi obtida no solo sob sistema convencional no período do inverno. A maior ocorrência de ácaros foi no solo sob sistema orgânico no período do verão e a menor ocorrência foi no solo sob sistema convencional no inverno. Para os nematóides a maior ocorrência foi observada no verão em solo sob sistema convencional e a menor densidade foi obtida no inverno em solo sob sistema orgânico.

Palavras-chave: cafeicultura, esporos micorrízicos, nematóides, ácaro de solo.

\section{ABSTRACT}

The present work has the objective of studying the occurrence of these fungi, nematodes and acari in soils under different coffee growing systems in south of Minas Gerais State, in four distinct seasons: summer, autumn, winter and spring. Areas under the cultivation of coffee culture have been sampled under the system of zero-harvest, conventional and organic. For each of the soil samples collected in the layer of 0 to $20 \mathrm{~cm}$ the extraction of spores, nematodes and acari were collected, using the technique of humid sieving and centrifuging with saccharine at 50\%. The counting of the microorganisms was made by means of Petri dishes with vessels and the support of a stereoscope microscope. The management practices or cultivation systems adopted in each of the three areas in study presented influence in variations the density of the microorganisms analyzed during the four seasons of the year. The highest density of spores was obtained in the soil under the organic system during the period of autumn and 
the lowest average was obtained in the soil under the conventional system during winter. The largest occurrence of acari was in the soil under organic cultivation during summer and the smallest occurrence was obtained in the soil under the conventional system in winter. For the nematode the largest occurrence was in the soil under conventional cultivation during summer and the smallest occurrence was obtained in winter in the soil under the organic system.

Keywords: coffee growing, mycorrhizal spores, nematodes, acari in soil.

\section{INTRODUÇÃO}

O cafeeiro foi introduzido no Brasil, no Estado do Pará, por volta de 1.750, proveniente da Guiana Francesa pelo Capitão Mor Francisco de Mello Palheta. O café ainda ocupa um expressivo lugar de destaque no contexto econômico nacional, embora tenha diminuído sua participação no decorrer dos anos, devido à entrada de outros diversos produtos na pauta de exportação (Matiello et al., 2002).

Minas Gerais se destaca como o maior produtor de café do país, com uma participação em torno de $51 \%$ do café produzido (Mapa, 2009).

O soloéum dos principais recursos naturais finitos utilizados na exploração dos sistemas de cultivo cafeeiro, sendo considerado como base agrícola, pode também ser encarado como habitat de inúmeras e variadas populações de microrganismos de vida livre ou em associações com outros organismos que desempenham funções importantes nos ciclos biogeoquímicos e no funcionamento dos ecossistemas (Bell et al., 2005).

Os Fungos Micorrízicos Arbusculares (FMA) formam simbiose mutualística de caráter cosmopolita, com espécies presentes em $80 \%$ das famílias de plantas. Nessa simbiose, a planta supre o fungo com energia para crescimento e reprodução via fotossintatos, e o fungo provê a planta e o solo com uma gama de serviços
(Siqueira et al., 1989).

Dentre outros organismos presentes na cultura do café, destacam-se algumas espécies de ácaros que são pequenos invertebrados integrantes do filo Arthropoda, subfilo Chelicerata, classe Arachnida e subclasse Acari (Evans, 1992). Eles têm como principais características o reduzido porte e a ausência de segmentação (Moraes \& Flechtmann, 2008). De maneira geral, os ácaros podem ser agrupados em formas de vida livre e formas parasitas (Lopes Assad, 1997).

Os nematóides são microrganismos que vivem no solo e nas raízes das plantas em áreas cultivadas, como também em ambientes naturais e estão relacionados entre os animais multicelulares mais numerosos do mundo (Lordello, 1984). Espécies de vários gêneros de fitonematóides já foram encontradas parasitando o cafeeiro no Brasil, causando perdas de até $20 \%$ na produção. (Lordello \& Monteiro, 1974).

A utilização de microrganismos como aprimoramento tecnológico, com a finalidade de melhorar a disponibilidade de nutrientes às plantas, é uma prática potencialmente importante e muito necessária para a cultura cafeeira. Assim, este trabalho teve por objetivo estudar a ocorrência de FMAs, nematóides e ácaros em solos sob diferentes sistemas de cultivo cafeeiro no Sul de Minas Gerais.

\section{MATERIAL E MÉTODOS}

O trabalho foi desenvolvido nos municípios de Inconfidentes com latitude de $22^{\circ}$ $19^{\prime} 01$ ' S e longitude $46^{\circ} 19^{\prime} 40^{\prime \prime} \mathrm{O}$ e Ouro Fino com latitude $22^{\circ} 16^{\prime} 58^{\prime \prime} \mathrm{S}$ e longitude $46^{\circ} 22^{\prime}$ $08^{\prime \prime}$ O, localizados ao Sul do estado de Minas Gerais, região esta de clima tropical de altitude (Cwb), classificado segundo Köeppen (1931) com duas estações definidas: chuvosa e amena no verão (outubro a março) e seca com noites e madrugadas frias no inverno (abril a setembro), com média anual de precipitação de $1500 \mathrm{~mm}$ e temperatura média anual de $19^{\circ} \mathrm{C}$. 


\section{Descrição das Áreas de Cultivo em Estudo}

A área de produção Safra-zero está localizada no bairro Escolinha (Ouro Fino/ MG) dentro da Fazenda Mangará com a cultivar 'Mundo Novo' existente há doze anos em Argissolo Vermelho distrófico, segundo classificação de Prado (2005).

No município de Inconfidentes/MG localiza-se a Fazenda Experimental do Instituto Federal de Educação, Ciência e Tecnologia do Sul de Minas Gerais - Campus Inconfidentes com produção convencional de 'Icatu Amarelo', existente há cinco anos e a Fazenda Marcílio, na comunidade do Córrego da Onça com cultivo orgânico de 'Catuaí Amarelo Topázio', existente há oito anos, ambas em Latossolo Vermelho distrófico, classificados por Prado (2005).

\section{Amostragem dos solos em estudo}

Foram realizadas quatro amostragens em cada área de estudo, sendo realizada uma em cada estação do ano, consecutivamente nos meses de março e maio (período seco), julho e outubro (período chuvoso) de 2009. Em cada uma destas áreas, foi selecionado um quadrante de aproximadamente $1000 \mathrm{~m}^{2}$ (25linhas $\mathrm{x}$ 39plantas).

As amostras de solo para quantificar a ocorrência e distribuição de FMAs, nematóides e ácaros (ninfas) em solo foi realizada utilizando-se de um trado de amostragem de solo do tipo holandês. Foram amostrados 12 pontos por cultura, sendo em cada ponto retirada quatro sub amostras, na projeção da copa da planta, a uma profundidade de $0-20 \mathrm{~cm}$ em cada quadrante da planta. As 12 amostras compostas, retiradas de cada área e em cada estação, geraram aproximadamente $1 \mathrm{~kg}$ de solo cada, sendo em seguida acondicionadas em sacos plásticos e transportadas para o Laboratório de Biotecnologia do IFSULDEMINAS - Campus
Inconfidentes, onde foram armazenadas a $5^{\circ} \mathrm{C}$ em refrigerador, até o processamento.

\section{Extração e Quantificação de ácaros, esporos e nematóides}

As amostras de cada época ou período estudado foram submetidas ao peneiramento, em peneira com malha de $2 \mathrm{~mm}$ de diâmetro e secas ao ar por 12 horas. Em seguida, a densidade de ácaros (ninfas), esporos e nematóides foram avaliados, utilizando-se das doze repetições (amostras compostas) para cada área amostrada, contendo em cada repetição, $50 \mathrm{~mL}$ de solo, medidos em Becker de $100 \mathrm{~mL}$.

Os esporos foram extraídos pelo método do peneiramento úmido (Gerdemann \& Nicolson, 1963). O procedimento consistiu na transferência, separadamente, dos volumes das amostras citadas anteriormente para recipiente plástico de maior volume, onde as mesmas foram lavadas quatro vezes, sendo o sobrenadante resultante de cada lavagem, passado em peneiras de malhas $0,71,0,25$ e $0,053 \mathrm{~mm}$; o material retido na peneira de menor malha, foi acondicionado diretamente em tubos de centrífuga. Em seguida, os tubos foram balanceados com água destilada e centrifugados por 3 minutos a 3000 RPM. Em seguida, o sobrenadante dos tubos foi drenado cuidadosamente, sendo adicionada aos mesmos, uma solução de sacarose a $50 \%$ (Jenkins, 1964), agitando o conteúdo com auxílio de um bastão de vidro para serem centrifugados por 2 minutos a 2000 RPM. Após, o sobrenadante foi drenado com cuidado, na peneira de menor malha $(0,053 \mathrm{~mm})$. Posteriormente, o material foi lavado com água destilada e recolhido em recipientes plásticos com tampa e capacidade para $100 \mathrm{~mL}$, devidamente identificados com o nome, número da amostra e a data de realização da extração. Os recipientes foram armazenados a $5^{\circ} \mathrm{C}$ até a contagem microbiológica.

A contagem dos ácaros, esporos e 
nematóides foi realizada diretamente em placa canaletada com o auxílio de microscópio estereoscópico, assim como realizado por Silva et al. (2007).

\section{Delineamento Experimental}

O experimento foi conduzido esquema fatorial $4 \times 3$, sendo quatro estações de coleta analisadas (verão, outono e inverno) em três sistemas de cultivo estudados (safra-zero, convencional e orgânica), realizando-se doze amostras em cada por estação. Os dados foram submetidos à análise de variância (ANAVA) e as médias foram comparadas pelo teste de Scott-Knott a 5\% de significância, usando-se o programa Sisvar 4.0 (Ferreira, 2000).

\section{RESULTADOS E DISCUSSÕES}

Após análise dos dados encontrados nos experimentos efetuadas em quatro estações do ano que apresentou um teor médio de umidade de $23 \%$, foi possível constatar uma maior densidade de esporos e ácaros no sistema de produção orgânico e com uma menor densidade de nematóides. Em contrapartida, na produção convencional observou-se as menores densidades de esporos e ácaros e maior valor para nematóides (Tabela 01).

TABELA01. Númeromédiode esporosmicorrízicos, ácaros e nematóides presentes em $50 \mathrm{~mL}$ de solo sob sistemas de cultivo cafeeiro por ano.

\begin{tabular}{cccc}
\hline \multirow{2}{*}{$\begin{array}{c}\text { Sistemas de } \\
\text { cultivo }\end{array}$} & $\begin{array}{c}\text { Esporos } \\
\text { micorrízicos }\end{array}$ & $\begin{array}{c}\text { Ácaros de } \\
\text { solo }\end{array}$ & Nematóides \\
\cline { 2 - 4 } Convencional & $2,93 \mathrm{a}$ & $2,93 \mathrm{a}$ & $17,00 \mathrm{c}$ \\
Safra-zero & $7,06 \mathrm{~b}$ & $4,62 \mathrm{~b}$ & $13,31 \mathrm{~b}$ \\
Orgânico & $13,62 \mathrm{c}$ & $6,31 \mathrm{c}$ & $8,00 \mathrm{a}$ \\
\hline $\mathrm{CV}(\%)$ & 21,23 & 14,24 & 11,47 \\
Erro Padrão & 0,83 & 0,33 & 0,73 \\
\hline
\end{tabular}

Os FMAs e os nematóides parasitas de plantas podem estar simultaneamente associados às raízes, motivo pelo qual deve ser considerado o efeito combinado dos dois grupos de organismos sobre o desenvolvimento da planta. A maioria dos estudos envolvendo a interação micorriza-nematóide foi realizada com espécies de Meloidogyne (Reid, 1990). Nesse sentido, vários autores comprovaram que a associação micorrízica leva à redução dos danos produzidos por nematóides fitopatogênicos em diversas culturas.

As interações entre planta, nematóide, FMA e demais organismos da rizosfera, bem como os mecanismos envolvidos nesses processos, apresentam elevada complexidade, daí a necessidade de estudos integrados. Além disso, os FMA apresentam uma característica importante, a resistência a nematicidas (HABTE \& MANJUNATH, 1988).

\section{Esporos Micorrízicos}

Verificou-se no presente estudo que houve uma maior ocorrência de esporos no sistema de cultivo orgânico em todas as épocas estudadas, destacando-se no outono com média de 16,5 esporos, estação na qual todos os sistemas apresentaram uma tendência de maiores valores. A produção convencional apresentou os menores valores médios $(2,00)$ no inverno e sua maior densidade no outono $(3,75)$ e o sistema de produção safra-zero apresentou valores intermediários entre os demais sistemas de produção cafeeiros estudados (Tabela 02).

TABELA 02. Número médio de esporos micorrízicos presentes no solo sob sistemas de cultivo cafeeiro em três estações do ano.

\begin{tabular}{ccrcc}
\hline \multirow{2}{*}{$\begin{array}{c}\text { Sistemas de } \\
\text { cultivo }\end{array}$} & \multicolumn{4}{c}{ Número médio de esporos micorrízicos } \\
\cline { 2 - 5 } & Verão & Outono & Inverno & Primavera \\
\hline Convencional & $3,25 \mathrm{a}$ & $3,75 \mathrm{a}$ & $2,00 \mathrm{a}$ & $2,75 \mathrm{a}$ \\
Safra-zero & $7,75 \mathrm{~b}$ & $8,25 \mathrm{~b}$ & $5,50 \mathrm{~b}$ & $6,75 \mathrm{~b}$ \\
Orgânico & $14,75 \mathrm{c}$ & $16,50 \mathrm{c}$ & $10,75 \mathrm{c}$ & $12,50 \mathrm{c}$ \\
\hline $\mathrm{CV}(\%)$ & 19,12 & 20,61 & 21,75 & 20,58 \\
Erro Padrão & 0,82 & 0,97 & 0,66 & 0,75 \\
\hline
\end{tabular}

Colozzi-Filho (1999) observou em seus estudos que no verão (fev/1996) a esporulação 
no solo foi menor, pois é época de maior crescimento vegetativo das culturas e após o florescimento do cafeeiro, o número de esporos recuperados no solo foi maior, supostamente na época do outono, assemelhando-se aos resultados encontrados.

De modo geral, sabe-se que o efeito de pesticidas sobre os FMAs, pode variar de acordo com o modo de ação e da taxa de freqüência de aplicação (Siqueira, 1994).

\section{Nematóides}

Observou-se nos sistemas produtivos estudados uma maior densidade de nematóides na área de produção convencional, semelhantes aos valores do sistema safra-zero e os menores valores na produção orgânica, apresentando uma tendência dos maiores valores, para todos os sistemas, no verão (Tabela 03).

TABELA 03. Número médio de Nematóides presentes no solo sob diferentes sistemas de cultivo cafeeiro em quatro estações do ano.

\begin{tabular}{ccccc}
\hline \multirow{2}{*}{$\begin{array}{c}\text { Sistemas de } \\
\text { cultivo }\end{array}$} & \multicolumn{4}{c}{ Número médio de nematóides de solo } \\
\cline { 2 - 5 } & Verão & Outono & Inverno & Primavera \\
\hline Convencional & $18,5 \mathrm{~b}$ & $17,50 \mathrm{~b}$ & $15,25 \mathrm{~b}$ & $16,75 \mathrm{~b}$ \\
Safra-zero & $15,5 \mathrm{~b}$ & $13,75 \mathrm{~b}$ & $11,25 \mathrm{~b}$ & $12,75 \mathrm{~b}$ \\
Orgânico & $9,5 \mathrm{a}$ & $8,25 \mathrm{a}$ & $6,75 \mathrm{a}$ & $7,5 \mathrm{a}$ \\
\hline $\mathrm{CV}(\%)$ & 17,95 & 22,43 & 22,56 & 21,37 \\
Erro Padrão & 1,30 & 1,47 & 1,25 & 1,31 \\
\hline
\end{tabular}

$\mathrm{Na}$ maioria das vezes, o controle de fitonematóides em cafezais é ineficiente e em áreas contaminadas o controle da praga em bastante complexo (Gonçalves \& Silvarolla, 2001).

A sobrevivência de nematóides, na ausência do hospedeiro, é garantida em determinadas fases do ciclo de vida destes organismos, onde algumas espécies adotam estratégias de sobrevivência, destacando a dormência, que inclui quiescência e diapausa, garantido pelos ovos do gênero Meloidogyne, caso as condições sejam desfavoráveis (Amorim, 1995). A umidade é o fator abiótico que mais afeta as populações de nematóides (Norton, 1979).

Espécies de outros nematóides também são encontradas na rizosfera de cafeeiros (Garcia, 1987), porém Carneiro et al. (1992) em levantamento realizado em cafezais do Estado Paraná citaram a presença de $M$. exigua, $M$. incognita e de uma população de $M$. icognita com alguns caracteres morfológico atípicos. Otoboni et al. (1994) em áreas de café da estação Experimental do IAC-SP, constataram que a maioria das áreas estavam contaminadas por Meloidogyne spp.

\section{Ácaros de solo}

De acordo com os dados coletados foi possível observar que houve uma maior densidade de ácaros de solo no sistema de produção orgânico e os menores valores detectados na produção convencional, com uma tendência, para todos os sistemas de cultivo, dos maiores valores apresentados no verão (Tabela 04).

TABELA 04. Número médio de ácaros presentes no solo sob sistemas de cultivo cafeeiro em três estações do ano.

\begin{tabular}{ccccc}
\hline \multirow{2}{*}{$\begin{array}{c}\text { Sistemas de } \\
\text { cultivo }\end{array}$} & \multicolumn{4}{c}{ Número médio de ácaros em solo } \\
\cline { 2 - 5 } & Verão & Outono & Inverno & Primavera \\
\hline Convencional & $3,5 \mathrm{a}$ & $3,25 \mathrm{a}$ & $2,25 \mathrm{a}$ & $2,75 \mathrm{a}$ \\
Safra-zero & $5,5 \mathrm{~b}$ & $5,0 \mathrm{a}$ & $3,75 \mathrm{a}$ & $4,25 \mathrm{a}$ \\
Orgânico & $7,0 \mathrm{~b}$ & $6,5 \mathrm{a}$ & $5,5 \mathrm{~b}$ & $6,25 \mathrm{~b}$ \\
\hline CV(\%) & 27,95 & 31,62 & 28,18 & 33,96 \\
Erro Padrão & 0,74 & 0,77 & 0,54 & 0,75 \\
\hline
\end{tabular}

Ao estudar as espécies de ácaros associados ao cafeeiro em dois municípios de Minas Gerais, Pallini Filho et al. (1992) verificaram diferenças marcantes na composição das espécies, porém no presente estudo foi possível verificar apenas a presença de ninfas no solo, ou seja, ácaros em fase jovem, não demonstrando as diferenças na composição da acaro fauna dos locais em estudo.

Apesar de serem amplamente distribuídos geograficamente a densidade de ácaros de 
acordo com Krantz (1978), foi influenciada positivamente pelas melhores condições físicas e químicas como constatadas nos resultados dá análises das áreas cafeeiras em estudo e segundo Primavesi (1990) a grande densidade de ácaros no solo justifica-se pela alimentação disponível $\mathrm{e}$, quanto maior o teor de matéria orgânica e melhor a qualidade do solo, mais organismos haverá.

\section{CONCLUSÕES}

O sistema de manejo adotado em cada área estudada apresentou influência sobre a densidade de esporos micorrízicos, nematóides e ácaros.

Os maiores valores de densidade de esporos foram encontrados no período do outono, para todos os sistemas de produção.

As maiores densidade de nematóides e ácaros foram encontradas no período do verão, em todos os sistemas cafeeiros de produção.

O sistema de produção orgânico apresentou os maiores valores médios de ocorrência de esporos e ácaros, proporcionando a menor densidade de nematóides, independente da estação em estudo.

A área sob cultivo cafeeiro convencional proporcionou os menores números de esporos no inverno e ácaros no verão, apresentando os maiores valores médios de ocorrência de nematóides, também no verão.

O sistema de produção safra-zero apresentou todos os seus resultados médios com tendência ou semelhança ao sistema convencional, para as densidades de nematóides e ácaros.

\section{Agradecimentos.}

Os autores agradecem aos Cafeicultores que não mediram esforços e colaboraram de forma sobremaneira para a realização de trabalho: Fazenda Marcílio: Sr. Wilson de Freitas Marcílio; Fazenda Mangará: Sr. Francisco dos Reis Guimarães Filho.

\section{REFERÊNCIAS BIBLIOGRÁFICAS}

AMORIM, L. Sobrevivência do inóculo. In: BERGAMIN FILHO, A.; KIMATI, H.; AMORIM, L. (Eds.) Manual de Fitopatologia: Princípios e Conceitos. 3. ed. São Paulo. Agronômica Ceres. 1995. v.1, p. 246-267.

BELL, T.; NEWMAN, J. A.; SILVERMAN, B. W.; TURNER, S. I.; LILEY, A. K. The contribution of species richness and composition to bacterial services. Nature, v. 436, p. 11571160, 2005.

CARNEIRO, R.G.; ALTÉIA, A.A.K.; BRITO, J.A. Levantamento da ocorrência e da frequência de espécies e raças fisiológicas de Meloidogyne no Nordeste do Paraná. In: CONGRESSO BRASILEIRO DE NEMATOLOGIA, 16., 1992, Lavras. Resumos... Lavras: SBN, 1992. p. 44.

COLOZZI-FILHO, A. Dinâmica populacional de fungos micorrízicos arbusculares no agrossistema cafeeiro e adubação verde com leguminosas. Piracicaba : ESALQ, 106p. 1999 (Tese de Doutorado).

EVANS, G.O. Principles of acarology. Oxon: CAB International, 1992. 563p.

FERREIRA, D.F. Análises estatísticas por meio do Sisvar para Windows versão 4.0. In: REUNIÃO ANUAL DA REGIÃO BRASILEIRA DA SOCIEDADE INTERNACIONAL DE BIOMETRIA, 45., 2000, São Carlos. Anais... São Carlos, SP: UFSCar, 2000. p.255-258.

GARCIA, A. Levantamento da população de fitonematóides em lavouras de café da região de Marília. Jaboticabal, 1987. 36 f. Trabalho de graduação (Agronomia) - Faculdade de Ciências Agrárias e Veterinárias, Universidade 
Estadual Paulista, Jaboticabal, 1987.

GERDEMANN, J.W.; NICOLSON, T.H. Spores of mycorrhizal endogone species extracted from soil by wet sieving and decanting. Transactions of the British Mycological Society, Cambridge, v.6,p. 235-246, 1963.

GONÇALVES, W.; SILVAROLLA, M.B. Nematóides parasitos do cafeeiro. In: ZAMBOLIM, L. (Ed.). Tecnologias de produção de café com qualidade. Viçosa: UFV, Departamento de Fitopatologia, 2001. cap. 7. p. $199-268$.

HABTE, M.; MANJUNATH, A. Influence of phenamiphos on the vesicular-arbuscular mycorrhizal symbiosis in Leucaena leucocephala. Biology and Fertility of Soils. v.5, p.313-316, 1988.

JENKINS, W.R. A rapid centrifugal-floatation technique for separating nematodes from soil. Plant Disease Report, v.48, n.8,p.692-694, 1964.

KRANTZ, G.W. A manual of acarology. 2. ed. Corvallis: Oregon State University Book Stores, 1978. $509 \mathrm{p}$.

KÖEPPEN, W. Grundriss der Klimakunde. Zweite verbesserte auflage der "Klimate der Erde". Berlin: Walter De Gruite Co, 1931.

LOPES ASSAD, M.L. Fauna do solo. In: VARGAS, M.A.T.; HUNGRIA, M. (Ed.) Biologia dos solos dos Cerrados. Planaltina: EMBRAPA, CPAC, 1997. cap. 7, p.363-444.

LORDELLO, L.G.E. Nematóides das plantas cultivadas. 8 ed. São Paulo: Nobel, 1984. $314 \mathrm{p}$.

LORDELLO, L.G.E.; MONTEIRO, A.R. Informação preliminar sobre um nematóide nocivo ao cafeeiro. Piracicaba: Sociedade Brasileira de Nematologia, p. 13-15, 1974.

MAPA (Ministério da Agricultura, Pecuária e Abastecimento) Informe estatístico do café. Disponível em: http://www.agricultura. gov.br/pls/portal/docs/page/mapa/servicos/ portal_agronegocio_cafe/port_agro_cafe rel_estatisticas/informe $\% 20$ caf\%c $9 \% 20$ -\%20setembro-09_0.xls. Acesso em 20/10/2009.

MATIELLO, J.B.; SANTINATO, R.; GARCIA, A.W.R.; ALMEIDA, S.R.; FERNANDES, D.R. Cultura de café no Brasil: Novo manual de recomendações. Rio de Janeiro: Procafé, 2002. $387 \mathrm{p}$.

MORAES, G.J.; FLECHTMANN, C.H.W.; Manual de Acarologia. Acarologia básica e Ácaros de plantas cultivadas no Brasil. 1. ed. Ribeirão Preto, SP: Holos, Editora Ltda., 2008. v.1, 288p.

NORTON, D.C. Relationship of physical and chemical factors to populations of plant-parasitic nematodes. Annual Review of Phytopathology. v.17, p.279-299, 1979.

OTOBONI, C.E.M. Ocorrência de Fitonematópides e Identificação dos Fenótipos Isoenzimáticos de Meloidogyne spp. parasitos do cafeeiro na Estação Experimental de Pindorama (IAC) , SP. 1994. 61 f. Trabalho de Graduação (Agronomia) - Faculdade de Ciências Agrárias e Veterinárias, Universidade Estadual Paulista, Jaboticabal, 1994.

PALLINI FILHO, A.; MORAES, G.J.; BUENO, V.H.P. Ácaros associados ao cafeeiro (Coffea arabica L.) no sul de Minas Gerais. Ciência \& Prática, v.16, p.303-307, 1992.

PRADO, H. Solos do Brasil: gênese, morfologia, classificação, levantamento, manejo. 4.ed. Piracicaba, 282 p., 2005. 
PRIMAVESI, A. Manejo ecológico: a p.427-435, 2007.

agricultura em regiões tropicais. São Paulo:

Nobel, 1990, 549p.

SIQUEIRA, J.O. Micorrizas arbusculares.

In.: ARAUJO, R.S.; HUNGRIA, M.

REID, C.P.P. Mycorrhizas. In: LYNCH, S.M. Microrganismos de importância agrícola. (Ed.) The Rhizosphere. London. Wiley-Liss. Brasília: Embrapa, p.151-194, 1994. 1990. p.282-315.

SILVA, L.X.; FIGUEIREDO, M.V.B.; SILVA, SIQUEIRA, J.O; COLOZZI-FILHO, A.; OLIVEIRA, E. Ocorrência de micorrizas vesicular-arbusculares em agro e ecossistemas do Estado de Minas Gerais. Pesquisa G.A; GOTO, B.T.; OLIVEIRA, J.P.; BURITY, H.A. Fungos micorrízicos arbusculares em áreas de plantio de leucena e sabia na estado de Pernambuco. Revista Arvore, Viçosa, v.31, Agropecuária Brasileira, Brasília, v.24, p.1499-1506, 1989. 